\title{
Using the Medicare Current Beneficiary Survey to conduct research on Medicare-eligible veterans
}

\author{
Yvonne Jonk, PhD; ${ }^{\text {* }}$ Heidi O’Connor, MS; ${ }^{1}$ Tamara Schult, MPH; ${ }^{2}$ Andrea Cutting, MA; ${ }^{2}$ Roger Feldman, \\ PhD; ${ }^{3}$ Diane Cowper Ripley, PhD; ${ }^{4}$ Bryan Dowd, PhD $^{3}$ \\ ${ }^{1}$ Rural Health Research Center, Division of Health Policy and Management, School of Public Health, University of \\ Minnesota, Twin Cities Campus, Minneapolis, MN; ${ }^{2}$ Center for Chronic Disease Outcomes Research, Minneapolis \\ Department of Veterans Affairs Medical Center, Minneapolis, $M N ;{ }^{3}$ Division of Health Policy and Management, \\ School of Public Health, University of Minnesota, Minneapolis, MN; ${ }^{4}$ Health Services Research and Development/ \\ Rehabilitation Research and Development Rehabilitation Outcomes Research Center, North Florida/South Georgia \\ Veterans Health System, Gainesville Division, Gainesville, FL
}

\begin{abstract}
The Medicare Current Beneficiary Survey (MCBS) is a longitudinal, multipurpose panel survey of a nationally representative sample of Medicare beneficiaries sponsored by the Centers for Medicare and Medicaid Services (CMS). The MCBS serves as a comprehensive data source on self-reported health and socioeconomic status, health insurance, healthcare utilization and costs, and patient satisfaction. CMS uses Medicare claims data to validate self-reported Medicare FeeFor-Service (FFS) utilization. Because the Veterans Health Administration (VHA) does not bill for services, CMS imputes VHA costs. This article addresses the quality of the MCBS dataset for conducting research on Medicare-eligible veterans by addressing the sample's representativeness, quality of selfreported data, and accuracy of imputed VHA cost estimates. We compared demographic data from the 1992 and 2001 National Survey of Veterans (NSV) with the MCBS 1992 and 2001 Cost and Use files. We compared self-reported VHA utilization and CMS's imputed costs with VHA administrative datasets. The VHA's Pharmacy Benefits Management (PBM) database is available from fiscal year (FY) 1999 onward, and the VHA Health Economics Resource Center's (HERC) Average Cost datasets are available from FY1998 onward. While the samples were comparable in terms of age, sex, and race, the MCBS respondents were in better health, less likely to be married, and more likely to be widowed than NSV respondents. MCBS underreporting rates were higher for VHA than Medicare outpatient events. Underreporting and differences between CMS's and HERC's costing methodologies contributed to
\end{abstract}

lower MCBS versus VHA administrative person- and eventlevel costs. Alternatively, average annual VHA prescription costs per capita were higher in the MCBS than in the PBM data. Differences in socioeconomic characteristics of the NSV and MCBS samples may be attributable to differences in sampling methodologies. Higher underreporting rates for VHA versus Medicare FFS outpatient events are likely due to systemic differences between the VHA and private healthcare sectors. While VHA formulary discounts may not be reflected

\footnotetext{
Abbreviations: $\mathrm{CBOC}=$ Community-Based Outpatient Clinic, CMS = Centers for Medicare and Medicaid Services, CPT = Current Procedure and Terminology, DSS = Decision Support System, FFS = Fee-For-Service, FY = fiscal year, HERC = Health Economics Resource Center, LOS = length of stay, MCBS = Medicare Current Beneficiary Survey, NPCD = National Patient Care Database, NSV = National Survey of Veterans, OPC = outpatient care, $\mathrm{PBM}=$ Pharmacy Benefits Management, PSSG = Planning System Support Group, PTF = Patient Treatment File, SC = service connected, VA = Department of Veterans Affairs, VHA = Veterans Health Administration.

* Address all correspondence to Yvonne Jonk, PhD; University of Minnesota-Rural Health Research Center, 2520 University Avenue SE, Suite 201, Minneapolis, MN 55414; 612-623-8312; fax: 612-623-8324. Email: vjonk@umn.edu DOI:10.1682/JRRD.2009.10.0174
} 
in MCBS's VHA prescriptions costs, lower PBM prescriptions costs are also due to deficient indirect cost data. Since reliable VHA utilization and cost data existed in either FY1998 or FY1999 onward, study goals include estimating the relative share and/or cost of care provided by Medicare and the VHA. Researchers with access to VHA datasets should consider merging them into the MCBS and replacing self-reported utilization and CMS's imputed costs with VHA administrative data. This replacement would significantly improve the accuracy, quality, and usefulness of the MCBS dataset for policy research.

Key words: database, data quality, health insurance, health services for the elderly, healthcare costs, healthcare surveys, Medicare, Medicare Current Beneficiary Survey, Department of Veterans Affairs, veterans, Veterans Health Administration.

\section{INTRODUCTION}

Subject to eligibility guidelines, veterans who have served on Active Duty in the U.S. Armed Forces, in the military reserves, or in the National Guard are entitled to receive medical care through a nationwide network of Veterans Health Administration (VHA) facilities in the Department of Veterans Affairs (VA). The VHA is one of the world's largest healthcare systems, spending approximately $\$ 40$ billion in fiscal year (FY) 2008 (i.e., October 1, 2007-September 30, 2008) to provide healthcare to over 5 million veterans, or about 22 percent of the nation's veterans [1]. While the VHA was initially focused on providing inpatient care, this focus was broadened to include the full spectrum of care, including outpatient and pharmaceutical services, in the 1990s [26]. Medicare-eligible veterans are an exclusive group in that they are dually eligible to receive comparable sets of services through two Federally funded programs, Medicare and the VHA [7-15]. Medicare covers health services provided by the private sector, whereas the VHA serves as an important safety net [16-23], especially for veterans who are disabled and service connected (SC) for injuries or disease incurred or aggravated in military service, in lower socioeconomic status, in poorer health, and/or suffering from chronic conditions [24-27].

Datasets facilitating the conduct of research addressing the utilization and cost of services provided to veterans in multiple sectors of the healthcare market are limited. Sponsored by the Centers for Medicare and Medicaid Services (CMS), the Medicare Current Beneficiary
Survey (MCBS) dataset is unique in that it offers researchers access to the full spectrum of public and private sector healthcare utilization and costs, along with measures of health and functional status, access to care, and patient satisfaction for a nationally representative sample of Medicare beneficiaries [28-29]. The MCBS dataset contains a set of questions identifying veterans who have served in the U.S. Armed Forces, including their period of service, SC status, and VHA medical care service use. Because survey respondents are followed for a minimum of 4 years and the survey has been conducted since 1992, the MCBS dataset serves as a multipurpose panel survey that can support both cross-sectional and longitudinal analyses of the size of the safety net provided by the VHA to Medicare-eligible veterans. Thus, the MCBS is a rich, comprehensive data source uniquely suited to addressing VHA and Medicare policy-related questions, such as the effect of changes in program eligibility on utilization and costs, the effect of opening new facilities on access to care, and the potential benefits of comanaging care.

Adler [29] and Eppig and Chulis [30] describe the utility of the MCBS dataset for general research purposes. Studies using the MCBS dataset for research involving veteran subjects have addressed the effect of VHA eligibility reform on veteran Medicare beneficiaries' healthcare utilization and cost, the use of prescription drugs by veterans with diabetes, and the use of preventive services by elderly male veterans [31-33].

The primary objective of this study is to address the utility of using the MCBS dataset for research focused on Medicare-eligible veterans' utilization and cost of VHA and Medicare health services. Our specific aims are to-

1. Assess the completeness of the MCBS dataset by describing the degree of missing MCBS data for variables typically used in economic analyses predicting utilization and cost.

2. Compare the socioeconomic characteristics of the MCBS sample of veterans to the National Survey of Veterans (NSV) and address the MCBS sample's representativeness.

3. Validate the self-reported utilization and imputed cost estimates by addressing the degree of concordance between MCBS, VHA, and Medicare Fee-For-Service (FFS) administrative datasets regarding:

a. Veterans' use of VHA services (person-level estimates).

b.Veterans' levels of VHA and Medicare FFS services used (event-level estimates). 
c.CMS's imputed VHA cost estimates in the MCBS and VHA Health Economics Resource Center (HERC) average costs (considering per capita and event-level costs).

In the "Methods" section, we describe the sample population, the exclusion criteria, and the datasets used to address each of the study aims (i.e., the MCBS, NSV, and VHA administrative datasets). We then present the results of the analyses addressing each of the study aims, followed by a discussion of potential solutions to the problems encountered for research purposes.

\section{METHODS}

\section{Sample Population and Exclusion Criteria}

CMS selected the MCBS sample from Medicare enrollment files to be representative of the Medicare population. The sample was selected using a stratified, unequal probability, multistage probability design that consists of aged and disabled beneficiaries enrolled in Medicare Part A (hospital insurance), Part B (medical insurance), or both and residing in households or longterm care facilities in the United States and Puerto Rico. Disabled persons aged $<65$ and very old persons aged $\geq 85$ are oversampled. ${ }^{*}$ MCBS respondents are typically followed for 4 years. Our study sample contains approximately 29,756 person-years of data on veterans identified over an 11-year time span (1992-2002). Assuming that researchers using the MCBS data are interested primarily in analyzing veterans' utilization of services and their associated costs and/or health outcomes, determining a veteran's level of eligibility for accessing VHA services is critical. To illustrate this point, within the time frame of this study, the eligibility of non-SC means-tested veterans (i.e., VHA Priority Groups 7 and 8) has changed

\footnotetext{
*Because of the MCBS's complex design, researchers need to weight the sample so that estimates of population totals, percentages, means, ratios, and counts of persons and events are representative and generalizable to the entire Medicare-eligible population. The weights reflect the overall selection probability of each sample person and include adjustments for survey nonresponse and stratified sampling design based on age, sex, race, region, and metropolitan area. CMS provides documentation and tables of weighted results that researchers can use to ensure that their statistical packages and programming methodologies are handling the weights correctly. We conducted all analyses using STATA v10 (Strata Statistical Software; College Station, Texas).
}

over the years, with eligibility granted in 1995, rescinded in 2003, and (partially) restored in 2009. SC veterans, on the other hand, historically have received priority status for VHA services. Thus, SC is the primary determinant (besides household income and assets required for VHA means testing) for establishing VHA eligibility and enabling access to VHA services. If veteran respondents did not answer the question regarding their SC status, we excluded them from the sample $(n=170)$. Since they represent $<1$ percent of the sample $(170 / 29,756=0.6 \%)$, this exclusion criteria did not significantly affect the representativeness or usefulness of the sample for analyzing veterans' utilization and costs.

Because the underlying health conditions of patients living in long-term care facilities lead to patterns of healthcare utilization and cost that differ significantly from community-dwelling veterans, we also excluded the institutionalized veterans $(n=1,080)$. The remaining sample of 28,506 person-years of data translates into data on 11,121 (unique) community-dwelling veterans, with 11 to 24 percent using VHA services between 1992 and 2002 (Table 1).

\section{Addressing Study Aim 1: Assessing Completeness of Medicare Current Beneficiary Survey Dataset}

The MCBS dataset consists of two files: the Access to Care files and the Cost and Use files. Data from the Access to Care files provide detailed information on the health and socioeconomic characteristics of beneficiaries, access to care measures, and satisfaction with medical care services received. The Cost and Use files contain a combination of survey-reported data, Medicare FFS claims data, and other data from CMS's administrative files. Data from the Cost and Use files have undergone a careful reconciliation process to identify healthcare services reported from bills and self-reported survey data. The files provide a complete account of all medical and pharmaceutical care services received, out-of-pocket expenses, amounts paid and/or covered by all third-party payers, and sources of coverage or payment, including the VHA. The files also contain information on long-term care services, supplementary health insurance, living arrangements, income, health status, and physical functioning. Thus, the Cost and Use files can support a much broader range of research and policy analyses on the veteran Medicare population than would be possible using either self-reported survey data or administrative billing data alone. 
JRRD, Volume 47, Number 8, 2010

Table 1.

Medicare Current Beneficiary Survey (MCBS) veteran sample size by Veterans Health Administration (VHA) use, 1992 to 2002.

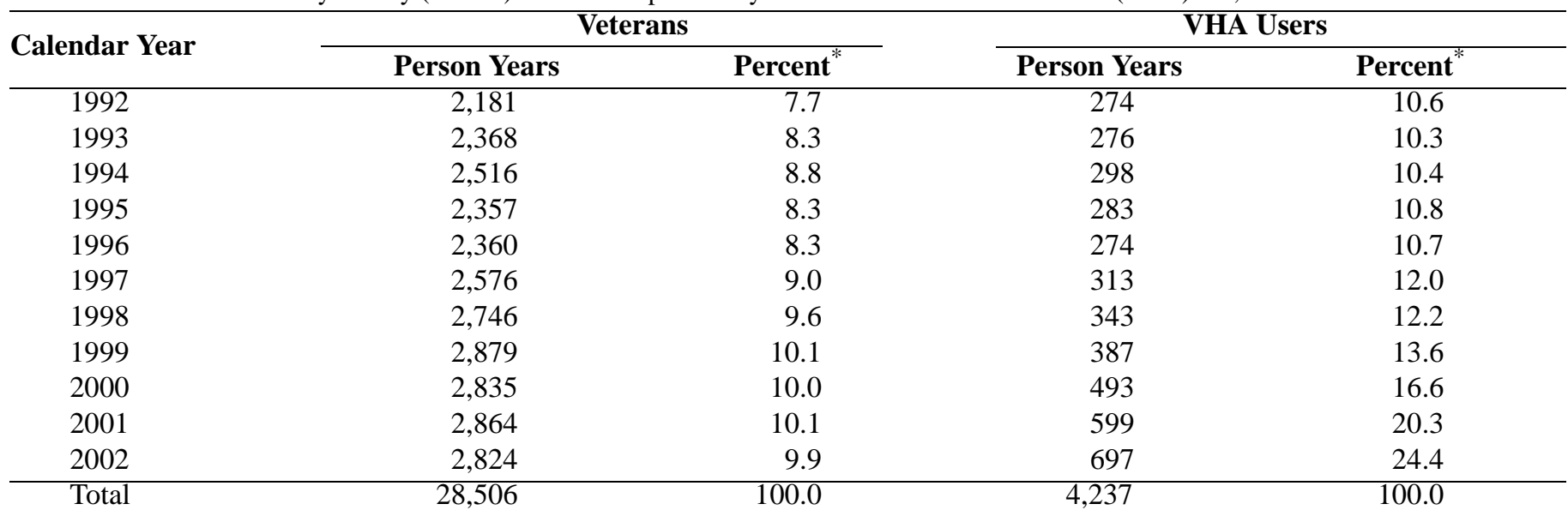

Notes: Sample consists of noninstitutionalized veterans in MCBS Cost and Use files. Since respondents are followed for 4 years, 28,506 person years of data translates into data on 11,121 unique veterans. VHA users are defined as anyone who has used any type of VHA service, including inpatient, outpatient, and/or prescription services. Percentages of VHA users have been weighted so that they are representative of general veteran Medicare population.

*Percentages may not add up to 100 due to rounding.

Since MCBS respondents are interviewed three times a year, the average interview recall period is about 4 months. Given normal rates of memory decay and the frequency with which older people and individuals with disability use medical care, underreporting of medical services is a problem. For Medicare FFS beneficiaries, CMS used Medicare FFS administrative claims data to flag selfreported and FFS comparable events, adjust for underreporting, and validate MCBS self-reported payment amounts. This event-level validation procedure employed "strength of evidence" criteria and hierarchical algorithms described in the MCBS technical documentation [28].

For health services not covered by Medicare FFS plans, including services provided to individuals enrolled in Medicare Advantage plans and/or Medicaid, no independent source of data could be used to match and verify use and payment information. When payment amounts were not reported by survey respondents within the MCBS sample population, CMS used a computer-intensive iterative imputation technique to fill in missing payment data for likely payers and sources of coverage [28].

The MCBS utilization and cost data are organized to reflect the unit of observation as a person (calendar) year. For researchers interested in predicting utilization and cost, the MCBS dataset contains a set of socioeconomic variables, insurance coverage, indications of health and functional status, and chronic conditions typically used for risk adjustment purposes.
Socioeconomic variables include sex, age, race, marital status, education, income, and family size. Since the MCBS dataset has the patients' addresses and zip codes, researchers can calculate the distance traveled to the nearest VHA medical facility as a measure of veterans' time and travel costs associated with seeing a VHA healthcare provider. ${ }^{*}$ Veterans' sources of insurance coverage other than Medicare FFS may include supplemental (Medigap) insurance coverage, enrollment in Medicare Advantage Plans, Medicaid, and/or the VHA at any time during the past calendar year. Researchers can create variables indicating the numbers of months per year with Medicare Part A only (not enrolled in Part B), Medigap coverage, and prescription drug coverage.

Measures of health status in any given year include VHA SC disability (Yes/No) and rating (scale of 0-100), general health status (excellent, very good, good, fair, or poor), functional status, chronic conditions, current and

\footnotetext{
* Researchers with access to VA data can obtain lists of current VHA medical facilities from the VHA's Site Tracking System updated and maintained by the VA Planning System Support Group (PSSG), a field unit of the Assistant Deputy Under Secretary for Health for Policy and Planning. Available upon request, the PSSG has a historical VA facility file for FY2002 onward containing VA facility codes, addresses, zip codes, and latitude and longitude coordinates. The distance between the patient's home address and zip code and the nearest VA facility can be calculated using a recently developed distance function available in SAS V9.2 (SAS Institute Inc; Cary, North Carolina).
} 
former smoking status, and death. Measures of functional status include activities of daily living (scale of $0-5$ ) and independent activities of daily living (scale of $0-6$ ), where higher scores indicate lower health status. Chronic conditions include heart condition, hypertension, stroke, cancer (including skin), diabetes, arthritis, lung disease, Alzheimer disease, and mental illness.

In terms of using these variables in economic analyses of utilization and costs, we address the completeness of the dataset by describing the percentage of the data that is missing.

\section{Addressing Study Aim 2: Comparing Socioeconomic Characteristics of National Survey of Veterans and Medicare Current Beneficiary Survey Samples}

The 2001 NSV is the fifth in a series of periodic comprehensive surveys conducted by the VA targeting noninstitutionalized veterans of the U.S. uniformed services living in private households in the United States, including Puerto Rico. The NSV serves as the VA's primary data source for describing veterans' military background, education and training, healthcare usage, and use of a broad array of VA benefits [34].

The NSV utilizes a dual-frame sample design consisting of a random-digit dialing sample of noninstitutionalized veterans living in the United States and Puerto Rico with (landline) telephone numbers and a list sample of veterans in the VHA Healthcare enrollment file and the Veterans Benefits Administration Compensation and Pension file. One of the questions in the NSV addresses health insurance and asks the respondent, "Are you currently covered by Medicare?” This question was revised in 2001 to distinguish between Medicare Parts A and B coverage as follows: "Medicare Part A pays for hospital care. Are you currently covered by Medicare Part A?" and "Medicare Part B pays for visits to doctor offices. Are you currently covered by Medicare Part B?" If the respondent is aged $\geq 65$ and/or confirms coverage through Medicare, we included them in our analysis of Medicareeligible veterans.

While approximately 35 percent of veterans were classified as eligible for Medicare in 1992, the Medicareeligible population grew to 41 percent of veterans in 2001. In this study, we compared the demographic characteristics of the sample of veteran respondents in the 1992 and 2001 NSV to the Medicare-eligible veterans within the MCBS Cost and Use Files for 1992 and 2001, respectively, by using tests for differences in means and proportions.

\section{Addressing Study Aim 3(a-b): Validating Self- Reported Use of Veterans Health Administration and Medicare Fee-For-Service Services}

Since validation studies generally find that selfreported healthcare utilization measures are consistently underreported [35-40], we compared self-reported use of VHA services in the MCBS dataset with events recorded in VHA administrative datasets by linking these data with use of a crosswalk file provided by the VA Information Resource Center [41]. We then identified veterans in the MCBS dataset as VHA users and nonusers by querying their use of VHA medical care facilities and verifying their self-reported use with that found in VHA administrative databases. As mentioned, CMS used Medicare FFS administrative claims data to flag self-reported and FFS comparable events. We used these flags to determine how often veteran Medicare FFS beneficiaries were not reporting (i.e., underreporting) FFS events and compared them with VHA underreporting rates.

Although we could have analyzed inpatient hospitalizations and outpatient count data for the entire time period that the MCBS dataset had been collected, we limited our analyses to the years the VHA cost datasets were available. These limitations are described next.

Reflecting the VHA's evolution from a primarily hospital-based system to one providing the full spectrum of healthcare services, the VHA went through a series of administrative changes that included a commitment to improving the quality of their administrative datasets and reconfiguring the files in the mid to late 1990s. For services prior to FY1997 (i.e., before October 1, 1996), the inpatient Patient Treatment File (PTF) and outpatient care (OPC) SAS files can be used to verify self-reported use of VHA inpatient and outpatient services, respectively; Medical SAS datasets generated from the PTF and National Patient Care Database (NPCD) can be used to verify post-FY1997 inpatient and outpatient utilization, respectively (Table 2) [41]. The Medical SAS datasets are national files containing information on all outpatient healthcare visits, including date of visit, patient characteristics (such as age and sex), type of clinic visited, and diagnostic (International Classification of Diseases-9th revision, Clinical Modification) and Current Procedure and Terminology (CPT) codes. Prior to FY1997, the OPC SAS file contains limited information on the type of 
JRRD, Volume 47, Number 8, 2010

Table 2.

Data sources available for validating Medicare Current Beneficiary Survey’s (MCBS’s) self-reported utilization and imputed cost estimates.

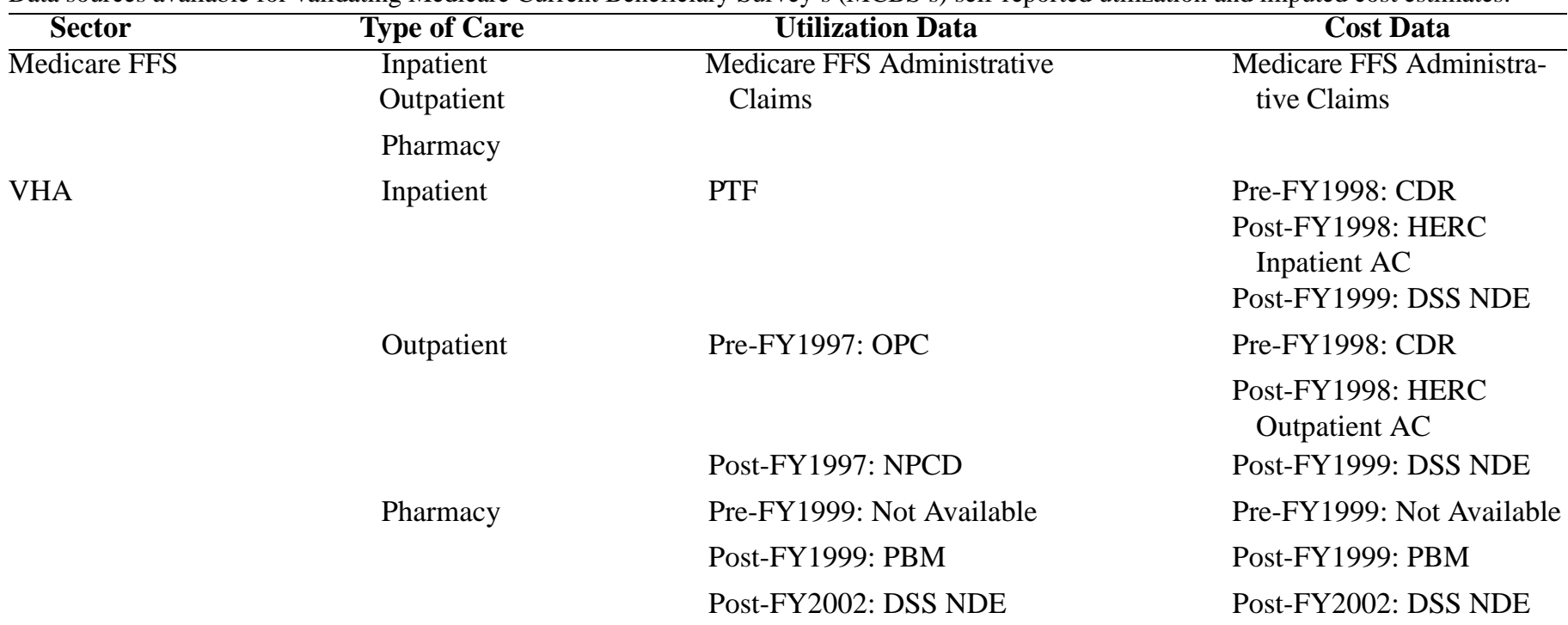

Note: Although DSS NDE files were not used in this study, they are a viable alternative source of VHA cost data.

AC = average cost, CDR = Cost Distribution Report, DSS $=$ Decision Support System, FFS $=$ Fee-For-Service, FY $=$ fiscal year, HERC $=$ Health Economics Resource Center, NDE = National Data Extracts, NPCD = National Patient Care Database, OPC = outpatient care, PBM = Pharmacy Benefits Management, PTF = Patient Treatment File, VHA = Veterans Health Administration.

facility where care was received (station codes), where care was received within that facility (stop codes), and the number of visits (and stops) by facility. While the VHA began to consistently record diagnostic and procedure codes in FY1997, the quality of this diagnostic information before FY1997 is poor. However, since studies analyzing changes in the number of overall outpatient visits, as well as primary care, specialty, surgical, and mental health care visits pre and post VHA reform efforts rely on clinic stop code information and not diagnostic and procedure codes, they are still enabled.

Since the VHA system is not comparable to the private system in the way clinic visits are scheduled (multiple clinical stops often are scheduled during a patient's 1-day visit to a VHA medical facility) and the way copayments are assessed (one copayment is assessed per any 1-day visit to a VHA facility), some ambiguity exists in what VHA patients perceive and self-report as an outpatient event. While some patients may report having seen three different VHA providers (i.e., three clinic stops and therefore three outpatient events) on any given day, for example, others may report a 1-day visit as one outpatient event regardless of the number of providers (clinic stops) they have seen that day. Thus, in addition to survey respondents' recall error, some measurement error undoubtedly exists. When analyzing the MCBS self- reported data, analysts have no way of knowing a priori whether the veteran respondent had been reporting clinic stops or day visits. Additionally, patients reporting when a specific outpatient event occurred may be off by a few days. The combination of measurement and recall errors has no discernable pattern, i.e., the errors do not consistently bias the utilization counts in any one direction. Therefore, establishing a set of rules that data analysts can use to sort out measurement error from recall error and matching a self-reported outpatient event to that found in the VHA administrative databases are very difficult, if not impossible. Thus, in this study, we compared the underlying distributional attributes of 1-day outpatient visits to a VHA facility as well as clinical events defined by clinic stop codes in the VHA's NPCD to the self-reported outpatient events found in the MCBS datasets.

The VHA began collecting prescription drug utilization data across all VHA sites in FY1999 (i.e., October 1, 1998), creating what is known as the VHA's Pharmacy Benefits Management (PBM) database [42]. Since prescription drug use was not consistently recorded in the Veterans' Health Information Systems Architecture before FY1999, nor have the data been consistently retained online for many years, no reliable source of VHA prescription drug utilization data at the national level is 
JONK et al. Using Medicare Current Beneficiary Study to conduct research

available before FY1999. Consequently, our analysis of the discrepancies between self-reported prescription drug use and prescription drug use found in the PBM are limited to FY1999 onward.

While very little ambiguity exists in how patients define and report hospitalizations, a variety of standardization issues come up when prescriptions are enumerated. For example, how does one account for 90- versus 30-day prescriptions, differences in dosages, and refills versus new prescriptions? Since patients are highly unlikely to consider these differences when asked to report their prescriptions, we took a simplistic approach and did not differentiate PBM prescriptions by pill quantity or dose.

\section{Addressing Study Aim 3(c): Validating Centers for Medicare and Medicaid Services' Imputed Veterans Health Administration Costs}

Since the VHA does not bill veterans for the services they receive, national VHA claims databases containing estimates of the cost of specific VHA events do not exist. The development of the VHA's HERC inpatient and outpatient cost estimates in FY1998 (i.e., October 1, 1997) onward facilitated the validation of CMS imputed costs in this study [43].

The HERC inpatient estimates represent the national average cost of a hospital stay for a given diagnosis related group, length of stay (LOS), and days in intensive care. The inpatient estimates are based on analyses of Medicare FFS cost-adjusted charges for veteran stays in non-VHA hospitals. The HERC outpatient file estimates represent the hypothetical average Medicare reimbursement for the CPT codes associated with the VHA visit. Hence, the resources used to provide VHA OPC are assumed to be proportionate to the relative values assigned in the Medicare reimbursement. Both inpatient and outpatient estimates are adjusted so that they tally up to annual national VHA expenditures by type of care [43-44].

The costs associated with VHA OPC before FY1998 are difficult to estimate because of the lack of relevant, consistent information on outpatient utilization in the VHA administrative files noted earlier. Without the added information associated with the diagnostic and procedural information, the cost estimates would have reflected the cost of an average stop code rather than average event-level costs and the variance associated with pre-FY1998 VHA outpatient cost estimates would be biased downwards. Thus, our validation of CMS's imputed VHA outpatient cost estimates was limited to FY1998 onward.

\section{RESULTS}

\section{Study Aim 1: Assessing Completeness of Medicare Current Beneficiary Survey Dataset}

In terms of the set of potential predictors of healthcare utilization and cost, issues with item nonresponse rates (i.e., missing data) were negligible. Out of the MCBS sample of 28,506 person-years, the data on age, sex, race, family size, household income, ever smoked, and insurance status (Medicare Advantage plans, Medicaid, supplemental policies) were 100 percent complete. Of the remaining set of potential predictors, $<1$ percent were missing: service era $(n=35$ out of 28,506 , or $0.12 \%)$; marital status ( $n=11,0.04 \%$ ); educational status $(n=113,0.40 \%)$; general health status $(n=87,0.31 \%)$; current smoker ( $n=33,0.12 \%$ ); and chronic conditions including heart condition, hypertension, stroke, cancer (including skin), diabetes, arthritis, lung disease, Alzheimer disease, and mental illness (range $n=1-11$, maximum $0.04 \%)$. Overall, this set of potential predictors resulted in a total of 776 person-years (2.7\%) of missing data.

\section{Study Aim 2: Comparing Socioeconomic Characteristics of National Survey of Veterans and Medicare Current Beneficiary Survey Samples}

For sex, age, and race, the demographic characteristics of the sample of Medicare-eligible veterans in the MCBS dataset were comparable to those in the 1992 and 2001 NSVs (Table 3). Of veterans in both samples and years, $>96$ percent were male, 92 to 93 percent of the sample were aged $\geq 65$ years, and 6 to 7 percent were between 45 and 64 years. Racially, the vast majority of individuals were white (91\%); 6 to 7 percent were African American. However, in both 1992 and 2001, the MCBS samples of veterans were less likely to be married, more likely to be widowed, more likely to report being in very good to excellent health, and less likely to report being in fair or poor health. Although the NSV and MCBS samples also differed in terms of their level of education, SC ratings, and use of VHA services in each time period, these differences were not consistent across the 1992 and 2001 time periods. We discuss possible reasons for differences between the survey populations in the "Discussion" section. 
JRRD, Volume 47, Number 8, 2010

Table 3.

National Survey of Veterans (NSV) and Medicare Current Beneficiary Survey (MCBS) sample characteristics, 1992 and 2001.

\begin{tabular}{|c|c|c|c|c|}
\hline \multirow{2}{*}{ Characteristic } & \multicolumn{2}{|c|}{1992} & \multicolumn{2}{|c|}{2001} \\
\hline & NSV & MCBS & NSV & MCBS \\
\hline Sample Size (person years) & 5,114 & 2,181 & 9,217 & 2,864 \\
\hline Male (\%) & 96.9 & 96.7 & 96.9 & 96.9 \\
\hline \multicolumn{5}{|l|}{ Age $(\%)^{*}$} \\
\hline 18-44 years & 1.4 & 1.1 & 1.3 & $0.8^{\dagger}$ \\
\hline 45-64 years & 5.9 & 6.1 & 7.0 & 6.2 \\
\hline$\geq 65$ years & 92.6 & 92.7 & 91.7 & $93.0^{\dagger}$ \\
\hline White (\%) & 91.3 & 91.5 & 91.2 & 91.5 \\
\hline Hispanic (any race, \%) & 2.9 & 2.8 & 1.2 & $3.8^{*}$ \\
\hline \multicolumn{5}{|l|}{ Education (\%) ${ }^{*}$} \\
\hline Less than High School & 30.3 & $35.5^{\dagger}$ & 20.4 & 24.0 \\
\hline High School Graduate (only) & 25.4 & $30.1^{\dagger}$ & 29.5 & 27.1 \\
\hline Some College & 24.7 & $15.3^{\dagger}$ & 27.4 & 26.1 \\
\hline College Graduate & 19.5 & 19.2 & 22.7 & 22.8 \\
\hline \multicolumn{5}{|l|}{ Marital Status (\%) } \\
\hline Never Married & 3.6 & 3.9 & 3.6 & 3.7 \\
\hline Married & 80.4 & $76.4^{\dagger}$ & 76.7 & $73.6^{\dagger}$ \\
\hline Divorced/Separated & 6.3 & $8.3^{\dagger}$ & 8.4 & 9.1 \\
\hline Widowed & 9.7 & $11.4^{\dagger}$ & 11.3 & $13.6^{\dagger}$ \\
\hline \multicolumn{5}{|l|}{ Health Status (\%) ${ }^{*}$} \\
\hline Excellent & 15.8 & $19.8^{\dagger}$ & 10.7 & $15.9^{\dagger}$ \\
\hline Very Good & 22.3 & $25.4^{\dagger}$ & 22.0 & $30.0^{\dagger}$ \\
\hline Good & 28.5 & 29.4 & 31.5 & 30.8 \\
\hline Fair & 19.3 & $16.7^{\dagger}$ & 22.6 & $15.6^{\dagger}$ \\
\hline Poor & 14.1 & $8.7^{\dagger}$ & 13.2 & $7.6^{\dagger}$ \\
\hline Have SC Rating? (Yes, \%) & 13.6 & 14.4 & 13.9 & $10.3^{\dagger}$ \\
\hline \multicolumn{5}{|l|}{ SC Rating (\%) } \\
\hline $1-25$ & 49.9 & $53.7^{\dagger}$ & 48.0 & $50.2^{\dagger}$ \\
\hline $26-50$ & 29.1 & $20.0^{\dagger}$ & 24.0 & $21.2^{\dagger}$ \\
\hline $51-75$ & 6.9 & $10.9^{\dagger}$ & 8.8 & $11.6^{\dagger}$ \\
\hline 76-100 & 14.2 & 15.3 & 19.2 & $17.0^{\dagger}$ \\
\hline Medicaid Coverage (\%) & 2.4 & 2.0 & 7.2 & $3.6^{\dagger}$ \\
\hline \multicolumn{5}{|l|}{ VHA Service Use Last Year (\%) } \\
\hline Inpatient & 2.7 & $2.4^{\dagger}$ & 3.3 & $1.5^{\dagger}$ \\
\hline Outpatient & 7.4 & $9.4^{\dagger}$ & 21.7 & $13.7^{\dagger}$ \\
\hline Prescription & NA & 7.8 & 16.6 & $19.1^{\dagger}$ \\
\hline
\end{tabular}

\section{Study Aim 3(a): Validation of Self-Reported Use of Veterans Health Administration Services (Person Level)}

At the group (sample population) level, the percentage of MCBS veterans who reported using VHA inpatient, outpatient, and prescription services was consistently underidentified in the MCBS dataset compared with the VHA administrative records. The largest discrepancies were for outpatient events. While 14 to 25 percent of MCBS veterans had VHA outpatient administrative 
claims in calendar years 1998 and 2002, respectively, only 11 to 17 percent self-reported using VHA outpatient services (Table 4).

\section{Study Aim 3(b): Validation of Self-Reported Levels of Veterans Health Administration and Medicare Fee- For-Service Use (Event Level)}

For veterans who had used Medicare and/or VHA services during the year, the number and percentage of events that were not reported (i.e., underreported) varied by type of care and by sector (Table 5). While underreporting was less of a problem for VHA than Medicare inpatient stays, veterans tended to underreport more VHA than Medicare outpatient events, regardless of whether a VHA outpatient event was defined as a day visit or a clinic stop. Underreporting was further ampli- fied when VHA outpatient events were defined by clinic stops. The average number of self-reported VHA inpatient stays, outpatient clinic stops, outpatient day visits, and prescriptions were consistently underreported compared with VHA administrative counts (Figures 1-4, respectively).

\section{Study Aim 3(c): Validation of Centers for Medicare and Medicaid Services' Imputed Veterans Health Administration Costs}

At the person level, we found large discrepancies between VHA and MCBS dataset estimates of average annual inpatient costs per capita (Table 6). The number of inpatient days per year was also underreported in the MCBS relative to VHA administrative datasets. The

Table 4.

Percent of veterans with Veterans Health Administration (VHA) events in Medicare Current Beneficiary Survey (MCBS) and VHA administrative databases, calendar years 1998 to 2002. Data shown as percent ( $n$ in person years)

\begin{tabular}{|c|c|c|c|c|c|c|c|c|c|c|}
\hline \multirow{3}{*}{ Event } & \multicolumn{2}{|c|}{1998} & \multicolumn{2}{|c|}{1999} & \multicolumn{2}{|c|}{2000} & \multicolumn{2}{|c|}{2001} & \multicolumn{2}{|c|}{2002} \\
\hline & VHA & MCBS & VHA & MCBS & VHA & MCBS & VHA & MCBS & VHA & MCBS \\
\hline & Data & Data & Data & Data & Data & Data & Data & Data & Data & Data \\
\hline Inpatient & $1.6(43)$ & $1.4(38)$ & $1.9(55)$ & $1.6(47)$ & $1.8(52)$ & $1.7(47)$ & $1.6(47)$ & $1.4(40)$ & $1.5(41)$ & $1.5(43)$ \\
\hline Outpatient & 13.9 (381) & $10.7^{*}(295)$ & $14.9(430)$ & $10.6^{*}(305)$ & $17.4(494)$ & $13.0^{*}(369)$ & $22.2(635)$ & $13.8^{*}(396)$ & $24.6(694)$ & $17.2^{*}(486)$ \\
\hline
\end{tabular}

Table 5.

Medicare Current Beneficiary Survey (MCBS) underreporting rates: percentage of events that were not reported by MCBS respondents, 1998 to 2002.

\begin{tabular}{|c|c|c|c|c|c|}
\hline \multirow{3}{*}{ Calendar Year } & \multicolumn{2}{|c|}{ Inpatient Stays } & \multicolumn{3}{|c|}{ Outpatient Events } \\
\hline & Medicare Stays & VHA Stays* & Medicare Events & VHA Day Visits* & VHA Clinic Stops ${ }^{*}$ \\
\hline & $(\%)$ & $(\%)$ & $(\%)$ & (\%) & $(\%)$ \\
\hline 1998 & 11.7 & -9.1 & 45.2 & 53.3 & 67.0 \\
\hline 1999 & 12.1 & 8.9 & 41.5 & 57.4 & 71.0 \\
\hline 2000 & 16.7 & 17.2 & 42.8 & 66.7 & 76.0 \\
\hline 2001 & 17.0 & 14.0 & 46.1 & 63.4 & 73.7 \\
\hline 2002 & 17.2 & 9.4 & 45.6 & 64.8 & 74.9 \\
\hline
\end{tabular}

Note: Self-reported events in MCBS were compared with Medicare Fee-For-Service and VHA administrative records. Higher percentages imply that more events were not reported, i.e., more events were underreported. Negative percents imply that patients reported more events than were recorded in administrative databases, i.e., they reported using more services than they actually did.

*Differences are significant at $p<0.05$.

VHA = Veterans Health Administration . 
JRRD, Volume 47, Number 8, 2010

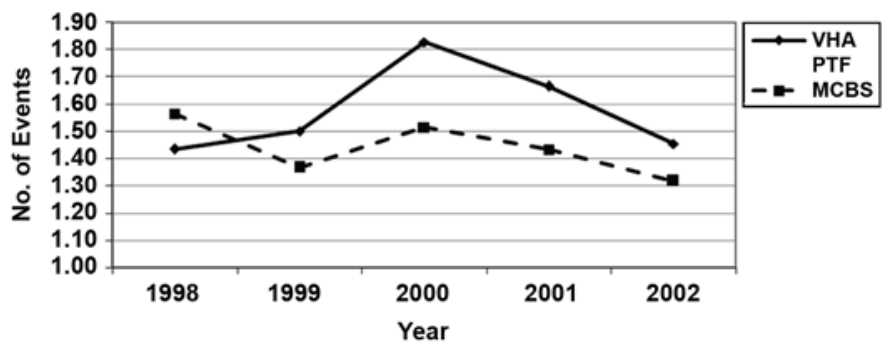

Figure 1.

Average number of Veterans Health Administration (VHA) inpatient events per person in Medicare Current Beneficiary Survey (MCBS) and VHA Patient Treatment Files (PTFs), 1998 to 2002.

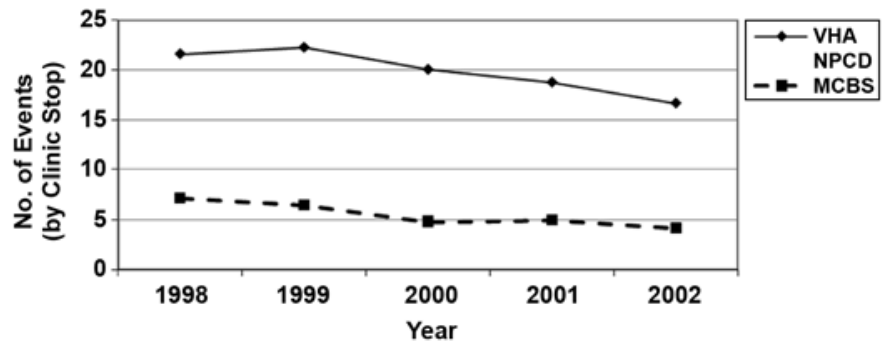

Figure 2.

Average number of Veterans Health Administration (VHA) outpatient events per person in Medicare Current Beneficiary Survey (MCBS) and VHA National Patient Care Databases (NPCD) by clinic stops, 1998 to 2002.

lower costs associated with VHA inpatient stays were further magnified by the underreporting issues realized in the utilization of VHA services by MCBS respondents (Figures 1 and 5).

At the event level, CMS's imputed VHA cost estimates were approximately $\$ 11,000$ to $\$ 16,500$ below the HERC's cost estimates for matching inpatient stays (Table 7). Even when the costs covered by all third-party payers involved in reimbursing the VHA inpatient stays was considered, CMS's imputed total cost estimates were still \$3,000 to \$15,000 lower than the HERC's cost estimates. Since inpatient costs are largely driven by LOS and per diem cost, while average self-reported LOS in the MCBS was significantly lower than the average LOS recorded in the VHA PTF in calendar years 1998 and 2000, it was higher in calendar years 1999, 2001, and 2002 (Table 7). Interestingly, CMS's average per diem cost estimates for either the amount paid by the VHA and/or the amount paid by all third-party payers were significantly higher than HERC’s per diem costs (Table 7).

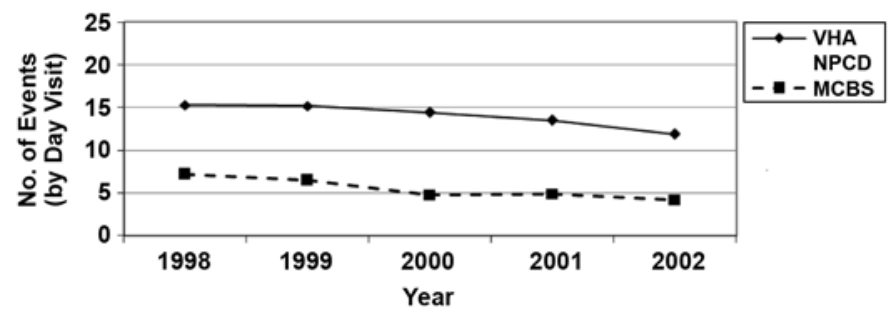

Figure 3.

Average number of Veterans Health Administration (VHA) outpatient events per person in Medicare Current Beneficiary Survey (MCBS) and VHA National Patient Care Database (NPCD) by day visits, 1998 to 2002.

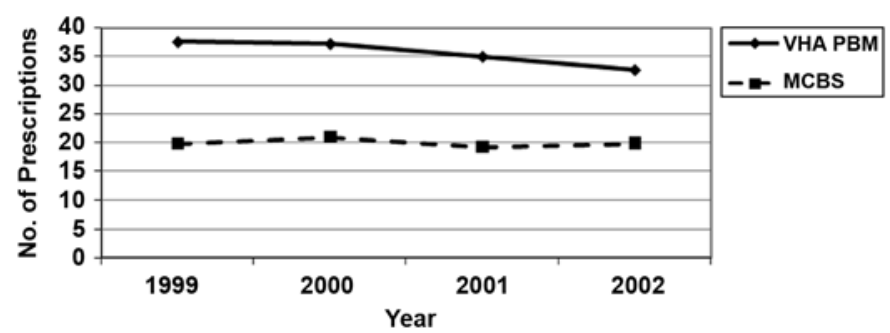

Figure 4.

Average number of Veterans Health Administration (VHA) prescriptions per person in Medicare Current Beneficiary Survey (MCBS) and VHA Pharmacy Benefits Management (PBM) datasets, 1999 to 2002.

Thus, neither of these two factors, LOS and/or per diem costs, appear to be driving the differences we observed between MCBS's and HERC's inpatient cost estimates.

While the distribution of CMS's imputed cost estimates for VHA outpatient services appeared reasonably close to the HERC Outpatient Average Costs (Table 8), because respondents tended to underreport their healthcare utilization in the MCBS, average annual outpatient costs per person were lower in the MCBS dataset than estimates using NPCD utilization and HERC Average Cost estimates (Figures 2, 3, and 6).

Alternatively, even though prescriptions were also underreported in the MCBS datasets, CMS's imputed costs for VHA prescriptions were significantly higher than PBM costs (Table 8). This contributed to CMS's estimates of average annual prescription costs per person being substantially higher than prescription costs for the same group of veteran respondents in the PBM files for calendar years 1998 to 2002 (Figures 4 and 7). 
JONK et al. Using Medicare Current Beneficiary Study to conduct research

Table 6.

Average annual Veterans Health Administration (VHA) inpatient costs (in dollars), number of inpatient days, and number of inpatient stays per person using VHA and Medicare Current Beneficiary Survey (MCBS) data, 1998 to 2002.

\begin{tabular}{|c|c|c|c|c|c|c|c|}
\hline \multicolumn{2}{|c|}{ By Person } & \multicolumn{3}{|c|}{ VHA Data } & \multicolumn{3}{|c|}{ MCBS Data } \\
\hline $\begin{array}{c}\text { Calendar } \\
\text { Year }\end{array}$ & $\begin{array}{l}\text { Sample } \\
\text { Size }\end{array}$ & $\begin{array}{c}\text { HERC } \\
\text { Average Cost } \\
\text { (mean } \pm \text { SD) }\end{array}$ & $\begin{array}{c}\text { Inpatient Days } \\
(\text { mean } \pm \text { SD) }\end{array}$ & $\begin{array}{c}\text { Inpatient } \\
\text { Stays } \\
\text { (mean } \pm \text { SD) }\end{array}$ & $\begin{array}{c}\text { CMS Imputed } \\
\text { VHA Cost } \\
\text { (mean } \pm \text { SD) }\end{array}$ & $\begin{array}{c}\text { Inpatient Days } \\
\text { (mean } \pm \text { SD) }\end{array}$ & $\begin{array}{c}\text { Inpatient } \\
\text { Stays } \\
\text { (mean } \pm \text { SD) }\end{array}$ \\
\hline 1998 & 24 & $17,301 \pm 23,551$ & $17.5 \pm 28.0$ & $1.5 \pm 0.9$ & $4,210 \pm 3,131$ & $10.3 \pm 10.0$ & $1.6 \pm 1.2$ \\
\hline 1999 & 32 & $17,759 \pm 27,000$ & $18.3 \pm 31.3$ & $1.7 \pm 1.5$ & $5,368 \pm 5,820$ & $18.2 \pm 23.4$ & $1.4 \pm 0.9$ \\
\hline 2000 & 35 & $22,775 \pm 27,606$ & $30.5 \pm 56.8$ & $2.2 \pm 2.6$ & $8,037 \pm 10,141$ & $10.7 \pm 11.8$ & $1.5 \pm 0.8$ \\
\hline 2001 & 31 & $21,671 \pm 26,437$ & $14.2 \pm 20.3$ & $1.6 \pm 1.3$ & $5,205 \pm 5,197$ & $18.8 \pm 33.4$ & $1.5 \pm 1.2$ \\
\hline 2002 & 22 & $16,609 \pm 22,236$ & $12.5 \pm 19.1$ & $1.5 \pm 0.8$ & $5,573 \pm 5,565$ & $12.4 \pm 20.2$ & $1.3 \pm 0.6$ \\
\hline
\end{tabular}

Note: Differences in average annual costs per person are attributable to differences between CMS and HERC costing methodologies and to measurement and recall errors.

CMS = Centers for Medicare and Medicaid Services, HERC = Health Economics Resource Center, SD = standard deviation.

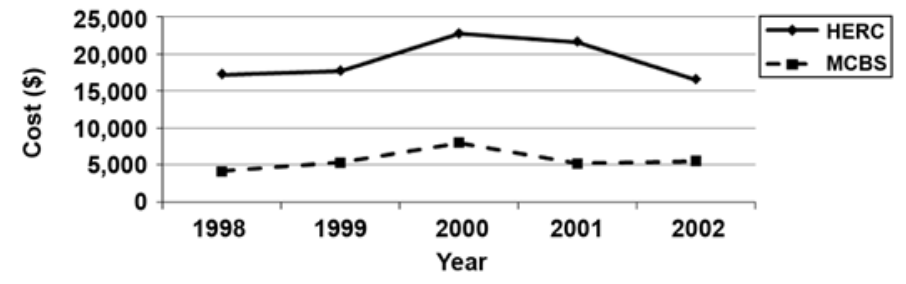

Figure 5.

Average annual per capita Veterans Health Administration (VHA) inpatient costs in Medicare Current Beneficiary Survey (MCBS) and VHA Health Economics Resource Center's (HERC's) average cost datasets, 1998 to 2002.

\section{DISCUSSION}

Since the item nonresponse rates were very low and resulted in a relatively small proportion of the MCBS veteran sample with missing data, generally speaking, this issue alone did not compromise the representativeness of the MCBS veteran sample. However, because we found significant differences in the demographic characteristics of the Medicare eligible samples of veterans in the MCBS and NSV, the representativeness of the two samples remains unclear. The analysis involved subsamples of survey respondents of both the MCBS (i.e., veterans) and the NSV (i.e., the elderly and disabled who are eligible for Medicare). Since the sampling methodologies for the two surveys differ, the two samples may not be directly comparable. However, the MCBS sampling strategy was specifically designed to ensure that the sample was representative of the Medicare population. Thus, the differences that we found are necessary but not sufficient to draw any conclusions regarding the representativeness of the MCBS sample of Medicare-eligible veterans.

Consistent with the literature on self-reported utilization, we found that VHA inpatient, outpatient, and pharmaceutical events in the MCBS dataset were underreported relative to the VHA administrative databases. Since the magnitude of the underreporting appears to be consistent over time, the results of studies focused solely on analyzing trends in VHA utilization using the MCBS selfreported VHA data should be valid. Although the data from the earlier time trends (calendar years 1992-1997) were not presented, the self-reported utilization data from these earlier years through 2002 were trending in the same direction.

Researchers interested in doing comparative research across Medicare and VHA sectors should be aware of the limitations associated with greater underreporting observed for VHA outpatient events. Much of these differences are likely due to systemic differences between the VHA and private systems of care, namely, financial incentives for patients to schedule multiple clinic stops during 1-day visits to VHA medical facilities.

In this study, we compared MCBS events with those in the VHA PTF, Event, Visit, and PBM files, and did not consider OPC provided under contract by non-VHA facilities. Underreporting issues may be further amplified 
Table 7.

Medicare Current Beneficiary Survey (MCBS) and Health Economics Resource Center (HERC) inpatient cost estimates (in dollars): differences in event costs, length of stay (LOS), and third-party payer reimbursements, 1998 to 2002.

\begin{tabular}{|c|c|c|c|c|c|c|c|c|c|}
\hline \multirow{2}{*}{\multicolumn{2}{|c|}{ By Event }} & \multirow{2}{*}{\multicolumn{3}{|c|}{ VHA Data }} & \multicolumn{5}{|c|}{ MCBS Data } \\
\hline & & & & & \multicolumn{3}{|c|}{ Event Cost Covered by All Payers } & \multicolumn{2}{|c|}{$\begin{array}{c}\text { Event Cost Covered by } \\
\text { VHA }\end{array}$} \\
\hline 1998 & 16 & $11,863 \pm 10,295$ & $12.0 \pm$ & דענ, & 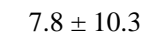 & $5,867 \pm 5,328$ & & $4,216 \pm 3,406$ & $1,289 \pm 1,319$ \\
\hline 2000 & 34 & $10,219 \pm 16,732$ & $13.7 \pm 28.2$ & $1,123 \pm 718$ & $6.3 \pm 9.4$ & $7,168 \pm 5,939$ & $3,356 \pm 3,848$ & $8,578 \pm 9,762$ & $3,907 \pm 5,373$ \\
\hline 2001 & 29 & $12,331 \pm 18,484$ & $10.7 \pm 19.2$ & $1,722 \pm 1,171$ & $13.4 \pm 19.9$ & $6,160 \pm 3,597$ & $1,601 \pm 1,556$ & $4,949 \pm 4,960$ & $1,272 \pm 1,790$ \\
\hline 2002 & 20 & $11,419 \pm 16,404$ & $8.6 \pm 15.2$ & $1,695 \pm 986$ & $9.7 \pm 19.8$ & $8,920 \pm 8,747$ & $2,862 \pm 3,864$ & $5,800 \pm 5,283$ & $1,827 \pm 2,086$ \\
\hline
\end{tabular}

Note: VHA inpatient stays in MCBS and VHA administrative datasets were matched by person and admission date. Since distribution of costs and LOS are not (typically) normally distributed, average per diem costs may not equal average total cost of stay divided by average LOS. MCBS data allocate cost of a healthcare event across each responsible third-party payer (i.e., insurance policy or program), while HERC's average cost datasets reflect 100\% of cost of VHA resources consumed during the VHA stay, regardless of payers involved. Thus, differences in event-level costs are attributable to differences in LOS, per diem costs, and costing methodologies.

$\underline{\mathrm{SD}}=$ standard deviation, VHA = Veterans Health Administration.

Table 8.

Distribution of Veterans Health Administration (VHA) and Medicare Current Beneficiary Survey (MCBS) outpatient and prescription costs per event, 1998 to 2002.

\begin{tabular}{|c|c|c|c|c|c|}
\hline \multirow{2}{*}{ Cost } & \multicolumn{5}{|c|}{ Year } \\
\hline & 1998 & 1999 & 2000 & 2001 & 2002 \\
\hline \multicolumn{6}{|c|}{ VHA: HERC Outpatient Average Cost } \\
\hline No. of Events & 6,033 & 6,439 & 7,017 & 7,222 & 7,794 \\
\hline Mean \pm SD (\$/Event) & $93.8 \pm 156.0$ & $101.6 \pm 222.1$ & $102.3 \pm 143.0$ & $114.3 \pm 166.8$ & $117.0 \pm 181.4$ \\
\hline Median (\$/Event) & 61.7 & 68.0 & 74.1 & 82.5 & 81.2 \\
\hline \multicolumn{6}{|c|}{ MCBS: CMS Imputed Outpatient Costs } \\
\hline No. of Events & 1,751 & 1,750 & 1,552 & 1,733 & 1,801 \\
\hline Mean \pm SD (\$/Event) & $121.0 \pm 339.6$ & $72.5 \pm 236.1$ & $110.8 \pm 318.8$ & $97.3 \pm 296.8$ & $121.4 \pm 741.0$ \\
\hline Median (\$/Event) & 15.3 & 13.4 & 28.6 & 24.5 & 20.0 \\
\hline \multicolumn{6}{|c|}{ VHA: PBM Prescription Costs } \\
\hline No. of Events & NA & 11,634 & 15,289 & 18,284 & 19,635 \\
\hline Mean \pm SD (\$/Event) & NA & $18.4 \pm 37.6$ & $21.3 \pm 72.0$ & $22.4 \pm 67.3$ & $23.4 \pm 63.2$ \\
\hline Median (\$/Event) & NA & 4.8 & 5.3 & 5.79 & 6.5 \\
\hline \multicolumn{6}{|c|}{ MCBS: CMS Imputed Prescription Costs } \\
\hline No. of Events & 5,650 & 7,724 & 9,109 & 10,761 & 5,650 \\
\hline Mean \pm SD (\$/Event) & $42.8 \pm 149.6$ & $44.1 \pm 81.2$ & $51.4 \pm 79.1$ & $50.3 \pm 75.5$ & $42.8 \pm 149.6$ \\
\hline Median (\$/Event) & 18.4 & 20.7 & 25.0 & 24.7 & 18.4 \\
\hline
\end{tabular}

Note: This comparison pertains to a group of veterans identified in both VHA and MCBS databases as having used VHA outpatient and prescription services, respectively. Number of events varies between VHA and MCBS data due to recall and measurement error.

CMS = Centers for Medicare and Medicaid Services, HERC = Health Economics Resource Center, NA = not available, PBM = Pharmacy Benefits Management, $\mathrm{SD}=$ standard deviation. 


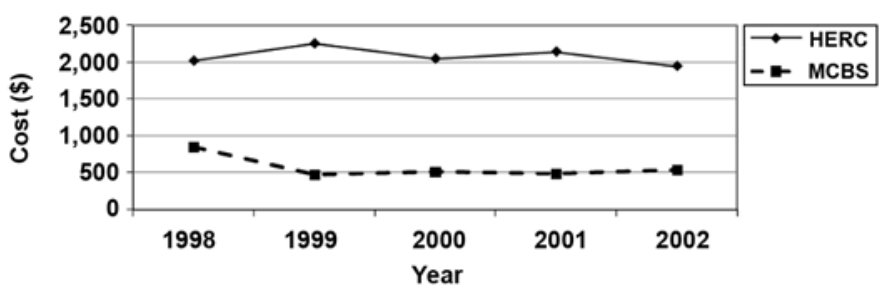

Figure 6.

Average annual per capita Veterans Health Administration (VHA) outpatient costs in Medicare Current Beneficiary Survey (MCBS) and VHA Health Economics Resource Center's (HERC's) average cost datasets, 1998 to 2002.

in rural areas where the VHA has concentrated on improving access to care by establishing contracts with Community-Based Outpatient Clinics (CBOCs). If these CBOCs are under contract to provide services through the VHA, veterans may not recognize or report these events as VHA events. Researchers interested in tracking contracted healthcare events will likely find them in the VHA's Fee Basis Files and not in the VHA's Medical SAS outpatient files generated from the NPCD.

A number of factors may help explain why the VHA's PBM prices are lower than CMS's imputed prescription costs. First, since the VHA is able to negotiate pharmacy formulary discounts, the VHA typically pays lower prices than Medicare for drugs commonly used by seniors. A study conducted by Families USA found a median difference of 46 percent between the VHA price and the lowest price paid by Medicare drug plans [45]. Second, although PBM costs reflect the direct cost of drugs paid by the VHA, the PBM costs do not include overhead or dispensing costs. Since the VHA's Decision Support System (DSS) dataset allocates indirect costs among VHA prescriptions, a comparison of DSS and PBM prescription costs found that indirect costs accounted for as much as 27.7 percent of the average cost of a VHA outpatient prescription in FY2002 [46]. Since CMS's imputed VHA prescription costs are likely based on prices realized by Medicare/non-VHA sectors of the healthcare market, the combination of the two factors described above, PBM's nonaccounting for indirect costs, and CMS's nonaccounting for the VHA's formulary discounts would have contributed to the discrepancies in prescription costs we observed.

Although discrepancies in hospitalization costs were partially attributable to differences between self-reported LOS and LOS recorded in the VHA PTF, the majority of

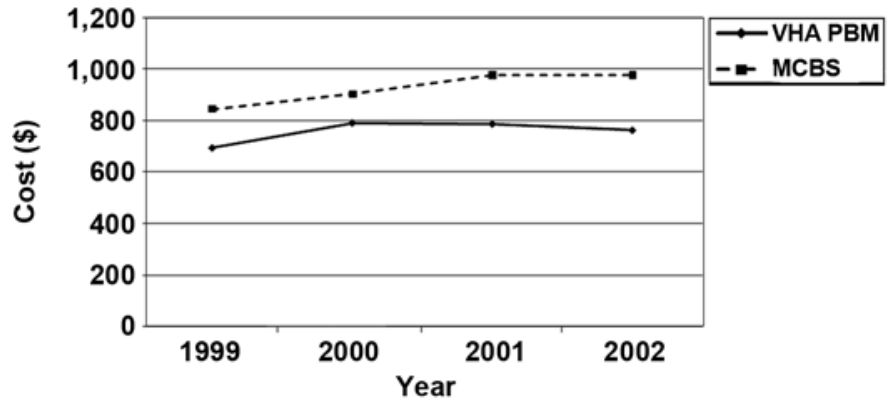

Figure 7.

Average annual per capita Veterans Health Administration (VHA) prescription costs in Medicare Current Beneficiary Survey (MCBS) and VHA Pharmacy Benefits Management (PBM) files, 1999 to 2002.

these differences are likely due to differences in CMS's and HERC's costing methodologies. In some years, as many as 75 percent of the VHA inpatient stays in the MCBS had split the cost of the stay between the VHA and the patient, attributing half of the cost of the stay as the patient's out-of-pocket expense. Although the VHA is allowed to bill veterans' private insurance for VHA services, they are not allowed to bill Medicare, nor is the VHA allowed to bill a veteran for the portion of the bill not covered by private insurance. In addition, for non-SC veterans, the VHA's copayments for hospitalizations are similar to Medicare's [47]. Splitting VHA hospitalization costs 50/50 with the patient and/or Medicare is not typical VA policy. Thus, we believe that CMS's inpatient costs lack the accuracy that VA researchers have come to appreciate when using VHA costing databases such as those developed by HERC.

This brings us to one of the more salient issues faced by policymakers: the relative proportion of the Federal budget spent on caring for elderly veterans through the VHA and Medicare. With more than a quarter of the Medicare population comprised of veterans as those proportions rise with the next generation of aging (Vietnam war) veterans, policies affecting access to VHA and Medicare services will affect utilization levels and thus both the VHA's and Medicare's budgets.

Since the MCBS consists of a nationally representative sample of Medicare-eligible veterans, the MCBS dataset is uniquely suited for analyzing the effect of changes in program eligibility, the effect of the expansion of medical facilities on access to care, and potential quality improvements associated with comanaging care provided by multiple providers and programs. In particular, changes 
in Medicare benefits may also lead to changes in the availability of supplemental coverage from former employers that, in turn, could affect decisions regarding where to seek care [48]. Because veterans consider the VHA an important source of coverage for prescription drugs, analyzing the effect of Medicare Part D on the use of VHA prescription services, for example, would inform the VHA of the potential effect on the VHA's (and Medicare's) medical expenditures.

Since the MCBS conducts a careful reconciliation process comparing self-reported utilization and cost data to Medicare FFS administrative claims data, the accuracy associated with the utilization and cost of Medicare FFS health services is ensured. We found that aside from the issue of under-reporting typically associated with selfreported data, CMS's imputed cost estimates suffer from substantial methodological issues and measurement error. Although CMS has tried to impute the amount paid by various payers for VHA events reported in the MCBS dataset, eligibility for VHA services and the mix of (private) payers the VHA is able to bill for VHA services, including patient copayments, is complex and not easily simulated. Not only is the scope of VHA healthcare benefits fairly complex, but the VHA has undergone significant administrative and eligibility reforms and has greatly evolved over time.

\section{CONCLUSIONS}

If the costs of VHA services, including inpatient hospitalizations, are critical to addressing study objectives, since inpatient stays are relatively expensive and can significantly influence study results, researchers should not rely on the MCBS's imputed VHA inpatient cost estimates. Reliable VHA utilization and cost data are available for all types of care (inpatient and outpatient care from FY1998 onward and prescriptions from FY1999 onward). Thus, for studies focusing solely on these later time periods, researchers with access to VHA datasets should merge these data into the MCBS. Since the methodology HERC used to estimate the value of VHA resources is based on Medicare relative value units, HERC's cost estimates for VHA services are comparable with Medicare cost estimates. While HERC cost estimates do not consider the mix of potential payers or the amount of out-of-pocket expenses veterans are responsible for, they do reflect the value of healthcare resources expended on behalf of caring for veterans. Comparisons of programmatic spending on the Medicare population would be greatly validated by merging in VHA cost estimates that accurately represent the VHA's dedication to improving, as well as maintaining, the health of this potentially vulnerable elderly veteran population.

\section{ACKNOWLEDGMENTS}

\section{Author Contributions:}

Study concept and design: Y. Jonk, R. Feldman, D. C. Ripley, B. Dowd.

Acquisition of data: Y. Jonk, H. O’Connor, T. Schult, A. Cutting, D. C. Ripley.

Analysis and interpretation of data: Y. Jonk, H. O’Connor, T. Schult, R. Feldman, D. C. Ripley, B. Dowd.

Drafting of manuscript: Y. Jonk, R. Feldman, D. C. Ripley, B. Dowd. Critical revision of manuscript for important intellectual content: Y. Jonk, R. Feldman, D. C. Ripley, B. Dowd.

Statistical analysis: Y. Jonk, H. O’Connor, T. Schult, R. Feldman, D. C. Ripley, B. Dowd.

Obtained funding: Y. Jonk, R. Feldman, D. C. Ripley, B. Dowd. Administrative, technical, or material support: Y. Jonk, A. Cutting. Study supervision: Y. Jonk.

Financial Disclosures: The authors have declared that no competing interests exist.

Funding/Support: This material is based on work supported by VA Health Services Research and Development Service (grant IIR 01-164) and presented, in part, at the VA HERC Cyber Seminar Series, April 2007.

Additional Contributions: The opinions are the authors' and do not reflect those of the VA, the VHA, or VA Health Services Research and Development Service. The authors would like to thank Todd Wagner, $\mathrm{PhD}$, Health Economist at HERC, for reviewing the tables comparing HERC average cost estimates and CMS imputed costs in the MCBS.

\section{REFERENCES}

1. Quality initiatives undertaken by the Veterans Health Administration. Washington (DC): Congressional Budget Office; 2009.

2. Sales AE. The Veterans Health Administration in the context of health insurance reform. Med Care. 2008;46(10): 1020-22. [PMID: 18815522] DOI:10.1097/MLR.0b013e318184aa75

3. Kizer KW. From the Veterans Health Administration. JAMA. 1996;275(14):1069. [PMID: 8601910$]$

4. Rosenheck R. Primary care satellite clinics and improved access to general and mental health services. Health Serv Res. 2000;35(4):777-90. [PMID: 11055448]

5. Veterans' health care: Facilities' resource allocations could be more equitable [Internet]. Washington (DC): General 
Accounting Office; 1996 [cited 2006 Oct 19]. Report No.: HEHS-96-48. Available from:

http://www.fas.org/man/gao/gao9648.htm.

6. Veterans health care eligibility reform act of 1996, Pub L No. 104-262, 110 Stat. 3177 (1996 Oct 9).

7. DeVito CA, Morgan RO, Virnig BA. Use of Veterans Affairs medical care by enrollees in Medicare HMOs. N Engl J Med. 1997;37(14):1013-14. [PMID: 9312676] DOI:10.1056/NEJM199710023371418

8. Fleming C, Fisher ES, Chang CH, Bubolz TA, Malenka DJ. Studying outcomes and hospital utilization in the elderly. The advantages of a merged database for Medicare and Veterans Affairs hospitals. Med Care. 1992;30(5):377-91. [PMID: 1583916] DOI:10.1097/00005650-199205000-00001

9. Hester EJ, Cook DJ, Robbins LJ. The VA and Medicare HMOs-Complementary or redundant? N Engl J Med. 2005;353(12):1302-3. [PMID: 16177262] DOI:10.1056/NEJMc051890

10. Passman LJ, Garcia RE, Campbell L, Winter E. Elderly veterans receiving care at a Veterans Affairs Medical Center while enrolled in Medicare-financed HMOs. Is the taxpayer paying twice? J Gen Intern Med. 1997;12(4):247-49. [PMID: 9127230]

11. Shen Y, Hendricks A, Li D, Gardner J, Kazis L. VAMedicare dual beneficiaries' enrollment in Medicare HMOs: Access to VA, availability of HMOs, and favorable selection. Med Care Res Rev. 2005;62(4):479-95.

[PMID: 16049135] DOI:10.1177/1077558705277396

12. Veterans' health care: Use of VA services by Medicareeligible veterans. Washington (DC): General Accounting Office; 1994 [cited 2006 Oct 19]. Report No.: HEHS-95-13. Available from: http://www.legistorm.com/ls score/gao/ pdf/1994/10/ful24841.pdf.

13. Weeks WB, Bott DM, Lamkin RP, Wright SM. Veterans Health Administration and Medicare outpatient health care utilization by older rural and urban New England veterans. J Rural Health. 2005;21(2):167-71. [PMID: 15859054] DOI:10.1111/j.1748-0361.2005.tb00077.x

14. Wright SM, Daley J, Fisher ES, Thibault GE. Where do elderly veterans obtain care for acute myocardial infarction: Department of Veterans Affairs or Medicare? Health Serv Res. 1997;31(6):739-54. [PMID: 9018214]

15. Wright SM, Petersen LA, Lamkin R, Daley J. Increasing use of Medicare services by veterans with acute myocardial infarction. Med Care. 1999;7(6):529-37. [PMID: 10386565] DOI:10.1097/00005650-199906000-00002

16. Wilson NJ, Kizer KW. The VA health care system: An unrecognized national safety net. Health Aff (Millwood). 1997;16(4):200-204. [PMID: 9248165]

DOI:10.1377/hlthaff.16.4.200
17. Borowsky SJ, Cowper DC. Dual use of VA and non-VA primary care. J Gen Intern Med. 1999;14(5):274-80.

[PMID: 10337036]

DOI:10.1046/j.1525-1497.1999.00335.X

18. Hoff RA, Rosenheck RA. The use of VA and non-VA mental health services by female veterans. Med Care. 1998; 36(11):1524-33. [PMID: 9821940] DOI:10.1097/00005650-199811000-00002

19. Hoff RA, Rosenheck RA. Female veterans' use of Department of Veterans Affairs health care services. Med Care. 1998;36(7):1114-19. [PMID: 9674628] DOI:10.1097/00005650-199807000-00017

20. Jonk Y, Call KT, Cutting AH, O’Connor H, Bansiya V, Harrison K. Health care coverage and access to care: The status of Minnesota's veterans. Med Care. 2005;43(8):769-74. [PMID: 16034290] DOI:10.1097/01.mlr.0000170403.97264.39

21. Kashner TM, Muller A, Richter E, Hendricks A, Lukas CV, Stubblefield DR. Private health insurance and veterans use of Veterans Affairs care. RATE Project Committee. Rate Alternative Technical Evaluation. Med Care. 1998;36(7): 1085-97. [PMID: 9674625] DOI:10.1097/00005650-199807000-00014

22. Piette JD, Heisler M. Problems due to medication costs among VA and non-VA patients with chronic illnesses. Am J Manag Care. 2004;10(11 Pt 2):861-68.

[PMID: 15609740]

23. Shen Y, Hendricks A, Zhang S, Kazis LE. VHA enrollees' health care coverage and use of care. Med Care Res Rev. 2003;60(2):253-67. [PMID: 12800686] DOI:10.1177/1077558703060002007

24. Agha Z, Lofgren RP, VanRuiswyk JV, Layde PM. Are patients at Veterans Affairs medical centers sicker? A comparative analysis of health status and medical resource use. Arch Intern Med. 2000;160(21):3252-57. [PMID: 11088086] DOI:10.1001/archinte.160.21.3252

25. Kazis LE, Miller DR, Clark J, Skinner K, Lee A, Rogers W, Spiro A 3rd, Payne S, Fincke G, Selim A, Linzer M. Health-related quality of life in patients served by the Department of Veterans Affairs: Results from the Veterans Health Study. Arch Intern Med. 1998;158(6):626-32.

[PMID: 9521227]

DOI:10.1001/archinte.158.6.626

26. Kazis LE, Ren XS, Lee A, Skinner K, Rogers W, Clark J, Miller DR. Health status in VA patients: Results from the Veterans Health Study. Am J Med Qual. 1999;14(1):28-38. [PMID: 10446661] DOI:10.1177/106286069901400105

27. Selim AJ, Berlowitz DR, Fincke G, Cong Z, Rogers W, Haffer SC, Ren XS, Lee A, Qian SX, Miller DR, Spiro A 3rd, Selim BJ, Kazis LE. The health status of elderly veteran enrollees in the Veterans Health Administration. J Am 
Geriatr Soc. 2004;52(8):1271-76. [PMID: 15271113] DOI:10.1111/j.1532-5415.2004.52355.X

28. Medicare Current Beneficiary Survey (MCBS) [Internet]. Washington (DC): Department of Health and Human Services, Centers for Medicare and Medicaid Services; 2005 [updated 2005 Dec 14; cited 2006 Oct 19]. Available from: http://www.cms.hhs.gov/mcbs.

29. Adler GS. A profile of the Medicare Current Beneficiary Survey. Health Care Financ Rev. 1994;15(4):153-63. [PMID: 10138483]

30. Eppig FJ, Chulis GS. Matching MCBS (Medicare Current Beneficiary Survey) and Medicare data: The best of both worlds. Health Care Financ Rev. 1997;18(3):211-29. [PMID: 10170350]

31. Jonk Y, Feldman R, Dowd B, Cowper-Ripley D, O’Connor $\mathrm{H}$, Cutting A, Schult $\mathrm{T}$. The impact of eligibility reform on demand for VHA services by Medicare eligible veterans. HERC CyberSeminar, April 25, 2007 [Internet]. Washington (DC): Health Services Research \& Development Service; 2007 [cited 2009 Oct 13]. Available from: http://www.hsrd.research.va.gov/for_researchers/ cyber seminars/catalog.cfm.

32. Tjia J, Briesacher BA. Prescription drug benefits and use of guideline recommended medications by elderly Medicare beneficiaries with diabetes mellitus. J Am Geriatr Soc. 2008; 56(10):1879-86. [PMID: 18771456]

DOI:10.1111/j.1532-5415.2008.01917.x

33. Keyhani S, Ross JS, Hebert P, Dellenbaugh C, Penrod JD, Siu AL. Use of preventive care by elderly male veterans receiving care through the Veterans Health Administration, Medicare fee-for-service, and Medicare HMO plans. Am J Public Health. 2007;97(12):2179-85. [PMID: 17971544] DOI:10.2105/AJPH.2007.114934

34. 2001 National Survey of Veterans: Final report. Washington (DC): Department of Veterans Affairs; 2002.

35. Yu ST, Chang HY, Lin MC, Lin YH. Agreement between self-reported and health insurance claims on utilization of health care: A population study. J Clin Epidemiol. 2009; 62(12):1316-22. [PMID: 19403264]

DOI:10.1016/j.jclinepi.2009.01.016

36. Short ME, Goetzel RZ, Pei X, Tabrizi MJ, Ozminkowski RJ, Gibson TB, Dejoy DM, Wilson MG. How accurate are self-reports? Analysis of self-reported health care utilization and absence when compared with administrative data. J Occup Environ Med. 2009;51(7):786-96. [PMID: 19528832] DOI:10.1097/JOM.0b013e3181a86671

37. Dubois MF, Raîche M, Hébert R, Gueye NR. Assisted selfreport of health-services use showed excellent reliability in a longitudinal study of older adults. J Clin Epidemiol. 2007; 60(10):1040-45. [PMID: 17884599] DOI:10.1016/j.jclinepi.2006.12.011
38. Bhandari A, Wagner T. Self-reported utilization of health care services: Improving measurement and accuracy. Med Care Res Rev. 2006;63(2):217-35. [PMID: 16595412] DOI:10.1177/1077558705285298

39. Raina P, Torrance-Rynard V, Wong M, Woodward C. Agreement between self-reported and routinely collected health-care utilization data among seniors. Health Serv Res. 2002;37(3):751-74. [PMID: 12132604] DOI:10.1111/1475-6773.00047

40. Wallihan DB, Stump TE, Callahan CM. Accuracy of selfreported health services use and patterns of care among urban older adults. Med Care. 1999;37(7):662-70.

[PMID: 10424637]

DOI:10.1097/00005650-199907000-00006

41. Veterans Affairs Information Resource Center (VIReC) [Internet]. Washington (DC): Department of Veterans Affairs; 2010 [updated 2010 Jan 13; cited 2009 Oct 13]. Available from: http://www.virec.research.va.gov/DataSourcesName/ DataNames.htm.

42. Pharmacy Benefits Management (PBM) services database [Internet]. Washington (DC): Department of Veterans Affairs; 2010 [updated 2010 Jan 13; cited 2009 Oct 13]. Available from: http://www.virec.research.va.gov/ DatasourcesName/DataNames.htm.

43. HERC average cost data [Internet]. Washington (DC): Department of Veterans Affairs; 2010 [updated 2010 Jun 22; cited 2010 Jan 1]. Available from: http://www.herc.research. va.gov/data/ac.asp.

44. Wagner TH, Chen S, Yu W, Barnett PG. HERC's average cost datasets for VA inpatient care FY1998-FY2008. Menlo Park (CA): Health Economics Resource Center; 2009.

45. Families USA. No bargain: Medicare drug plans deliver high prices [Internet]. Washington (DC): Families USA; 2007 [cited 2010 Mar 18]. Available from: http://www. familiesusa.org/assets/pdfs/no-bargain-medicare-drug.pdf.

46. Arnold N, Hynes DM, Stroupe KT. VIReC technical report 1: Comparison of VA outpatient prescriptions in the DSS datasets and the PBM database. Hines (IL): VA Information Resource Center; 2006.

47. Federal benefits for veterans, dependents and survivors [Internet]. Washington (DC): Department of Veterans Affairs; 2010 [updated 2010 Mar 16; cited 2010 Mar 23]. Available from: http://www1.va.gov/opa/publications/benefits book/benefits chap01.asp.

48. The potential cost of meeting demand for veterans' health care [Internet]. Washington (DC): Congressional Budget Office; 2005 [cited 2009 Oct 13]. Available from: http://www.cbo.gov/doc.cfm?index $=6171 \&$ type $=0$.

Submitted for publication October 26, 2009. Accepted in revised form May 13, 2010. 
This article and any supplementary material should be cited as follows:

Jonk Y, O’Connor H, Schult T, Cutting A, Feldman R, Ripley DC, Dowd B. Using the Medicare Current Beneficiary Survey to conduct research on Medicare-eligible veterans. J Rehabil Res Dev. 2010;47(8):797-814.

DOI:10.1682/JRRD.2009.10.0174

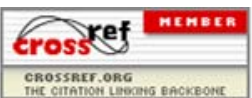


